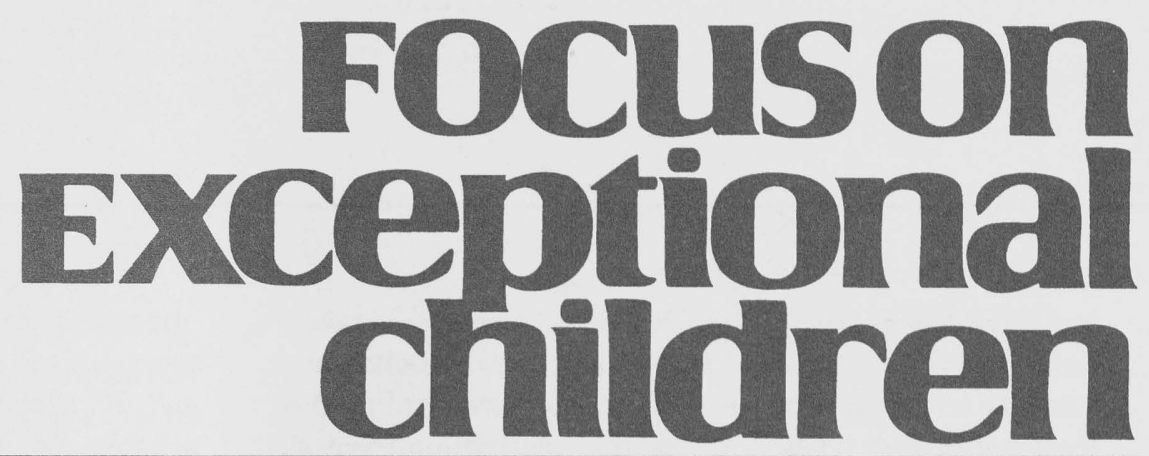

\title{
Principles for Sustaining Research-Based Practice in the Schools: A Case Study
}

\author{
Lynn S. Fuchs and Douglas Fuchs
}

Despite an impressive corpus of research on effective practices for school-age children with disabilities, this information finds its way into education practice only sporadically, even when the research has produced substantial knowledge related to problems of real-world importance (Fullan, 1991; Gersten, Woodward, \& Morvant, 1992; Huberman, 1983; Kaestle, 1993; Malouf \& Schiller, 1995). We offer the following as a case in point.

In 1985-86, we joined forces with our local, metropolitan public school district to develop a prereferral assessment process. The schools were interested in and supportive of our help because we were addressing one of their more pressing problems. The district recently had adopted a systemwide testing policy and more stringent standards for grade promotion, which resulted in more student retentions and teacher referrals to special education. We helped organize multidisciplinary, school-based teams, calling them MATs (Mainstream Assistance Teams), and trained them in behavioral consultation-a wellknown version of collaborative problem solving.

Despite training and onsite support, many MATs failed to design or execute effective interventions during the project's first year (Fuchs \& Fuchs, 1989; Fuchs \& Fuchs, 1988; Fuchs \& Fuchs, 1991). Moreover, teachers complained that the give-and-take nature of the consultation process took too long. Therefore, during the subsequent year, in search of more effectiveness and efficiency, we reduced membership in a MAT to a consultant and a consultee, and presented participants with a short list of empirically validated, detailed interventions from which to choose. Thus, we sacrificed some collaboration for the sake of accurate implementation of judiciously chosen interventions.

Our evaluation indicated that this more prescriptive approach strengthened the fidelity with which MAT interventions were implemented and their effectiveness (Fuchs, Fuchs, Bahr, Fernstrom, \& Stecker, 1990). Yet, problems remained. Teachers reported that improved behavior did not generalize, prescribed treatments were too complex, and the interventions still demanded too much time. So in the next year we again modified MATs to address these concerns (Fuchs, Fuchs, Gilman, et al., 1990; Fuchs, Fuchs, Bahr, et al., 1990). And results in this third year were positive: MAT prereferral interventions improved students' actual behavior as well as teacher perceptions of students. MAT also dramatically decreased special education referrals (Bahr, Fuchs, Fuchs, Fernstrom, \& Stecker, 1993; Fuchs, Fuchs, Bahr, et al., 1990).

Lynn Fuchs and Douglas Fuchs are affiliated with Peabody College of Vanderbilt University. 
Thus, after 3 years of R \& D, we had developed a prereferral intervention that worked for a majority of teachers and students. In fact, a survey of Utah teachers who had used at least one of five types of prereferral intervention (Nelson, Smith, Taylor, Dodd, \& Reavis, 1992) indicated that, in comparison to other well known strategies, teachers believed that MATs were more successful in maintaining difficult-to-teach students in the mainstream.

In a similar vein, Sindelar, Griffin, Smith, and Watanabe (1992), who reviewed prereferral intervention research, concluded that

\begin{abstract}
the work of the Fuchses ... [on MATs] stands out. Among other research questions, this group investigated the delivery of proposed remedial plans by classroom teachers...and the effectiveness of those plans. Effects were observed on goal achievement, student and teacher behavior change, and teacher and student satisfaction with the process. (p. 256)
\end{abstract}

Despite our relatively successful R \& D activity, this fact to consider: One year after the federal money for the MAT project ended, we could not find a single practitioner in the local school system implementing this demonstrably

\title{
Focuson
exceptional
children
}

ISSN 0015-511X FOCUS ON EXCEPTIONAL CHILDREN (USPS 203-360) is published monthly except June, July, and August as a service to teachers, special educators, curriculum specialists, administrators, and those concerned with the special education of exceptional children. This publication is annotated and indexed by the ERIC Clearinghouse on Handicapped and Gifted children for publication in the monthly Current Index to Journals in Education (CIJE) and the quarterly index, Exceptional Children Education Resources (ECER). The full text of Focus on Exceptional Children is also available in the electronic versions of the Education Index. It is also available in microfilm from Xerox University Microfilms, Ann Arbor, MI. Subscription rates: Individual, \$30 per year; institutions, $\$ 40$ per year. Copyright (c) 2001, Love Publishing Company. All rights reserved. Reproduction in whole or part without written permission is prohibited. Printed in the United States of America. Periodical postage is paid at Denver, Colorado. POSTMASTER: Send address changes to:

\section{Love Publishing Company}

Executive and Editorial Office P.O. Box 22353

Denver, Colorado 80222

Telephone (303) 221-7333

Karen Harris

University of Maryland
Thomas Skrtic University of Kansas

James Shriner

University of Illinois

Erica J. Lawrence Editor
Stanley F. Love Publisher effective practice. The disappearance of the MATs is noteworthy given that (a) we had trained 120 general educators and 30 support personnel in 34 elementary and middle schools, (b) the school district had serious concerns about referrals, and (c) we kept central administrators informed of findings. So why did teachers, support staff, and districtlevel administration fail to adopt or sustain use of MATs? And why do other demonstrably effective, research-based methods take root so infrequently in practice?

This article is dedicated to a discussion about how researchers and practitioners might work together more productively, in ways that not only result in validated tools (such as MATs) but also produce methods that schools continue to use after the researchers' work is completed. We begin by describing one research-based practice, Math PeerAssisted Learning Strategies (PALS), that, like MATs, was developed and researched in the Metropolitan-Nashville Public Schools. Unlike MATs, however, PALS continues to be used in many of the schools where it originally was developed and researched.

After describing Math PALS, we provide an overview of the model we used to develop and research the program. This model differs substantially from traditional research efforts because of its level of teacher involvement. We next present a case study of one school where Math PALS was developed, researched, and continues to be used. Finally, after presenting this case study, we highlight principles for sustaining the use of research-based practices, as illustrated in the case study.

\section{WHAT IS MATH PALS?}

In developing Math PALS, our goal was to help general educators differentiate their instruction in response to the learning of individual students. This goal can be difficult to achieve because general education planning is directed primarily to the class as a unit rather than to the individual, and because the general education classroom is characterized by wide heterogeneity in levels of students' academic competence.

We hoped to create a classroom "routine" that would be easy for teachers to use and children to learn and that automatically would incorporate feasible methods by which different children might work on different activities at the same time. In Math PALS, to provide frequent information about what parts of the curriculum students should be working on, we adapted curriculum-based measurement (CBM, Deno, 1985). To provide a classroom routine by which children could work on different activities at the same time, based on their needs, we adapted Juniper Gardens Classwide Peer Tutoring (Greenwood, Delquadri, \& Hall, 1989). 


\section{CBM}

Early in our efforts at using CBM within general education classrooms, we recognized that, to capture the attention of general educators, we had to present CBM information in terms of the performance of the class rather than the performance of 25 individual students. We focused teacher attention on individual students only selectively to highlight students in greatest need. This represented a radical departure from traditional CBM decision-making methods, which focus exclusively and intensively on individual students. Our CBM methods in the general education classrooms, therefore, comprise classwide weekly assessment, classwide biweekly student feedback, and classwide teacher reports.

\section{Weekly Assessment}

In terms of weekly assessment, teachers employ CBM to track pupil progress toward proficiency on the grade-level mathematics operations and applications curricula. Using a standard measurement task, teachers assess each pupil's performance weekly, each time on an alternative form of the test representing the grade-level's annual curriculum. For example, if the teacher teaches third grade, all students in the class are assessed each week with a parallel test that samples the third-grade types of problem in the proportion constituting the state's third-grade curriculum.

Each CBM assessment comprises approximately 45 problems; the exact number depends on grade level and remains constant within grade level. Problems are displayed in random order, encompassing randomly generated numerals. Performance is timed and scored as total number of correct responses. Teachers administer the weekly assessments in a whole-class format using an audiotape to signal the beginning and the end of the assessment. Each student's responses to all items are entered into a computer program that scores and manages the data.

\section{Student Feedback}

To provide student feedback, software summarizes each pupil's performance in terms of (a) a graph displaying the total number correct over time, and (b) a skills profile showing the student's mastery status on each type of problem included in the year's curriculum for each half-month interval in the school year (see Figure 1). Teachers instruct students on how to read and interpret graphs and skills profiles in two 20-minute sessions. In these sessions, teachers also teach students to ask themselves three questions about their graphs (Are my scores going up? What's my highest score? Can I beat my highest score in the next 2 weeks?) and about their skills profiles (Are my boxes getting darker? How many black or almost-black boxes do I have for this halfmonth? Which skills can I work harder on to get darker boxes the next half-month?). Every 2 weeks, when graph and skills profile feedback is provided to students, teachers remind students to ask themselves these questions.

\section{Teacher Reports}

Twice monthly, teachers print a copy of each student's graph and skills profile, as well as a teacher report summarizing the performance of the class (see Figures 2 through 6). This report includes:

1. A class graph displaying students' total number correct over time at the 25th, 50th, and 75th percentiles of the class (see Figure 2);

2. A list of pupils whose current performance fell below the 25th percentile (see Figure 3);

3. Lists of skills on which student performance had improved, stayed the same, and deteriorated over the past month (see Figure 3);

4. A class skills profile displaying every student's mastery status for the current half-month interval on each type of problem in the year's curriculum and providing a frequency count of the numbers of students in each mastery status for each type of problem (see Figure 3);

5. Rank-ordered students by their most recent score, which also shows the weekly rate of growth (see Figure 4). for:

The report also includes instructional recommendations

1. What to teach during whole-class instruction (see Figure 2);

2. How to constitute small groups of students for instruction on skills on which students experienced common chronic difficulty (see Figure 2);

3. Peer-assisted learning strategies, listing students who require and those who can provide assistance with which skills (see Figure 5).

In addition, the teacher report identifies students whose level of performance and rate of improvement in the curriculum is at least 1 standard deviation below that of classroom peers (see Figure 6).

\section{Peer Tutoring}

In addition, within every classroom, teachers incorporate two 35-minute peer-tutoring sessions each week into their allocated mathematics time. Teachers use peer tutoring to help remediate or to review portions of the curriculum already addressed during teacher-directed instruction. Teachers teach the tutoring routine to all children in their naturally constituted classes in five 30-minute sessions (see 

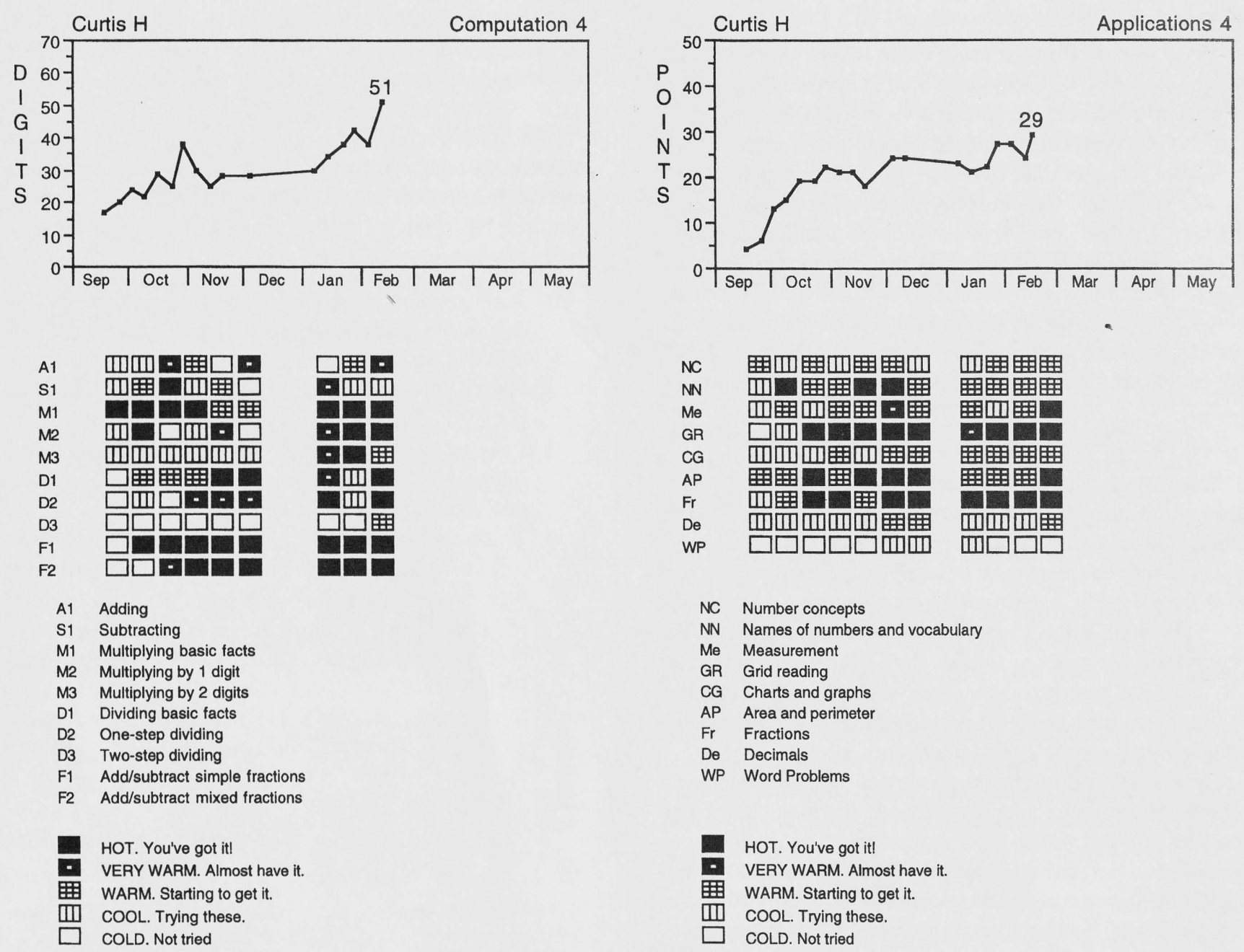

Note. Feedback includes information on overall growth over time (see graphs) and mastery status by objective over time (see grids).

FIGURE 1

\section{CBM Student Feedback on Computation and Concepts/Applications}

Fuchs, Fuchs, Karns, \& Phillips, 1994, for a manual).

With peer tutoring, every child in the class is paired to work with another child in the same class. Math PALS extends Juniper Gardens Classwide Peer Tutoring by employing a dyadic structure based on the following design features:

1. Mediated verbal rehearsal, in which the tutor models and gradually fades a verbal rehearsal routine delineating procedural steps for completing the type of problem;

2. Step-by-step feedback by the tutor to confirm and praise correct responses and to provide explanations and model strategic behavior for incorrect answers;
3. Frequent verbal and written interaction between tutors and tutees;

4. Opportunities for tutees to apply explanations in subsequent problems; and

5. Reciprocity, in which both children serve in the roles of tutor and tutee within each session.

These design features are incorporated into PALS based on research documenting the potential for mediated verbal rehearsal (Graham \& Harris, 1989; Zook \& DiVesta, 1989), appropriate feedback for learner responses (Walberg, 1984), opportunity for learner responding (e.g., Greenwood et al., 1989) and constructive activity following explanations 


\section{CLASS SUMMARY}

Teacher: Mrs. London

Report through $2 / 20$

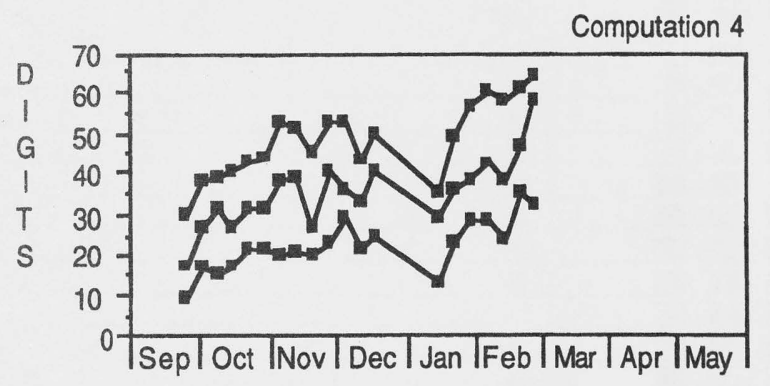

\section{Students to Watch}

\section{Douglas B}

Alicia L

Jeffrey B

Megan $\mathrm{H}$

Antonio F

\section{Areas of Improvement: Computation}
D2 One-step dividing
D3 Two-step dividing
S1 Subtracting
M1 Multiplying basic facts

\section{Whole-Class Instruction: Computation}

D3 Two-step dividing

$50 \%$ of your students are either COLD or

COOL on this skill.

\section{Small-Group Instruction: Computation}

D2 One-step dividing

Alicia L
Antonio F
Jeffrey B
Marcus R

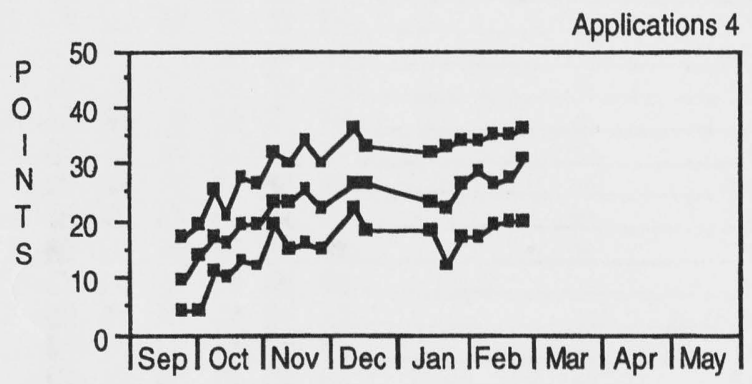

Most Improved

Douglas B
Megan H
Ben T
Amy C
Alicia L

Areas of Improvement: Applications

$\begin{array}{ll}\text { De } & \text { Decimals } \\ \text { Me } & \text { Measurement }\end{array}$

\section{Whole-Class Instruction: Applications}

De Decimals

$60 \%$ of your students are either COLD or COOL on this skill.

\section{Small-Group Instruction: Applications}

NC Number concepts

Antonio $\mathrm{F}$

Jeffrey $B$

Megan $\mathrm{H}$

Note. Page 1 of the class report shows the class graph in computation and concepts/applications, a list of students to watch (performance level in lowest quartile of the class), a list of the most improved students within the past month, skills on which the class as a whole has improved, skills for which whole-class instruction would be helpful, and skills for which small-group instruction would be helpful. 
CLASS SKILLS PROFILE - Computation

Teacher: Mrs. London

Report through 2/20

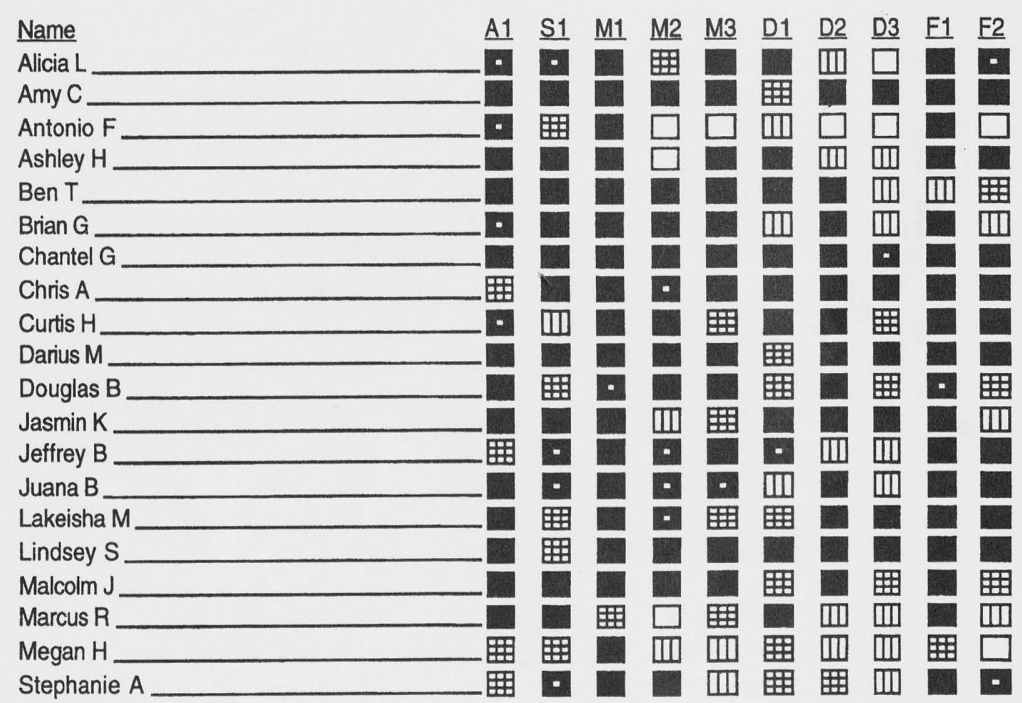

$\begin{array}{lrrrrrrrrrr}\square \text { COLD. Not tried } & 0 & 0 & 0 & 3 & 1 & 0 & 1 & 2 & 0 & 2 \\ \text { COOL. Trying these. } & 0 & 1 & 0 & 2 & 2 & 3 & 5 & 8 & 1 & 3 \\ \text { WIIRM. Starting to get it. } & 4 & 5 & 1 & 1 & 4 & 7 & 1 & 3 & 1 & 3 \\ \text { WERY WARM. Almost have it. } & 4 & 4 & 1 & 4 & 1 & 1 & 0 & 1 & 1 & 2 \\ \text { HOT. You've got it! } & 12 & 10 & 18 & 10 & 12 & 9 & 13 & 6 & 17 & 10\end{array}$

\section{CLASS SKILLS PROFILE - Applications}

Teacher: Mrs. London

Report through 2/20

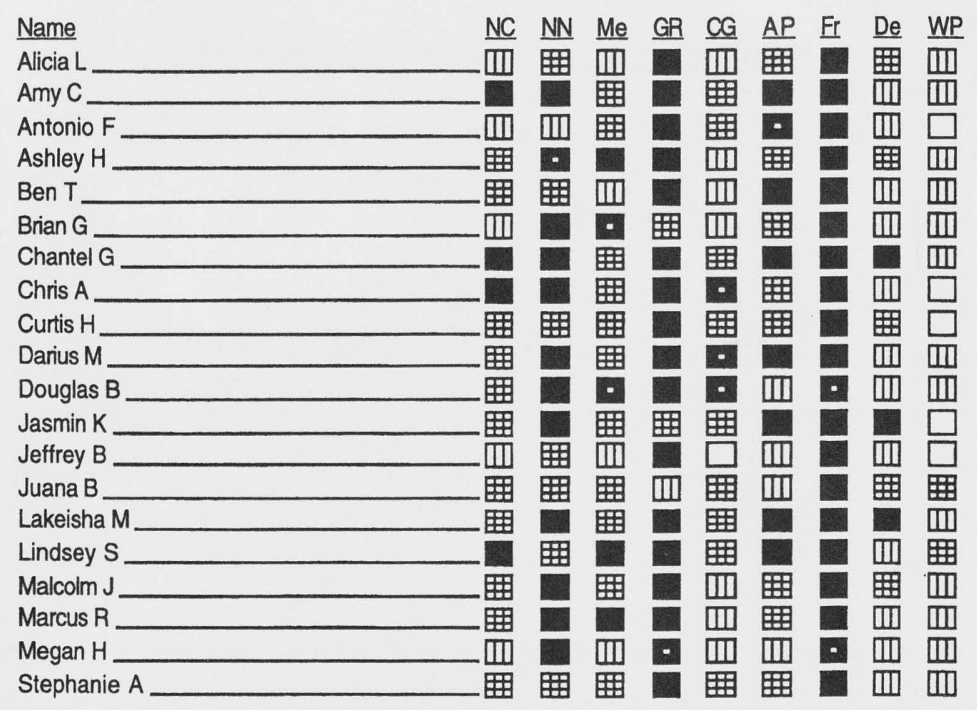

$\begin{array}{lrrrrrrrrr}\square \text { COLD. Not tried } & 0 & 0 & 0 & 0 & 1 & 0 & 0 & 0 & 5 \\ \text { COII COOL. Trying these. } & 5 & 1 & 4 & 1 & 7 & 4 & 0 & 12 & 13 \\ \text { WARM. Starting to get it. } & 11 & 7 & 11 & 2 & 9 & 8 & 0 & 5 & 2 \\ \text { - VERY WARM. Almost have it. } & 0 & 1 & 2 & 1 & 3 & 1 & 2 & 0 & 0 \\ \text { HOT. You've got it! } & 4 & 11 & 3 & 16 & 0 & 7 & 18 & 3 & 0\end{array}$

FIGURE 3

CBM Class Report, Pages 2 and 3 show skills profiles for the class 


\section{RANKED SCORES - Computation}

Teacher: Mrs. London

Report through 2/20

\begin{tabular}{|c|c|c|}
\hline Name & Score & Growth \\
\hline Amy C & 63 & +1.37 \\
\hline Darius $\mathrm{M}$ & 61 & +1.08 \\
\hline Malcolm J & 60 & +0.72 \\
\hline Lindsey S & 58 & +1.13 \\
\hline Chantel G & 55 & +1.04 \\
\hline Lakeisha M & -50 & -+0.42 \\
\hline Jasmin K & 50 & -+1.23 \\
\hline $\operatorname{Ben} T$ & -49. & +0.36 \\
\hline Chris A & -48 & +1.00 \\
\hline Juana B & -46 & +0.62 \\
\hline Curtis $\mathrm{H}$ & -44 & +1.01 \\
\hline Brian $G$ & -42. & +0.24 \\
\hline Ashley $\mathrm{H}_{\text {_ }}$ & -42 & +1.07 \\
\hline Marcus R & -41 & +0.98 \\
\hline Douglas $\mathrm{B}$ & -39 & +0.20 \\
\hline Alicia L & 39 & +0.49 \\
\hline Stephanie A & -37 & +0.26 \\
\hline Jeffrey B & 36 & +1.04 \\
\hline Megan $\mathrm{H}_{2}$ & 34 & +0.61 \\
\hline Antonio $\mathrm{F}$ & - & +0.24 \\
\hline
\end{tabular}

\section{RANKED SCORES - Applications}

Teacher: Mrs. London

Report through 2/20

\begin{tabular}{|c|c|c|}
\hline Name & Score & Growth \\
\hline Lindsey $S_{\text {_ }}$ & 35 & +0.69 \\
\hline Lakeisha M & 35 & +0.84 \\
\hline Chantel $G_{\text {. }}$ & 35 & +0.70 \\
\hline Amy C & 34 & +0.84 \\
\hline Jasmin $\mathrm{K}_{\text {_ }}$ & 33 & +0.87 \\
\hline Darius M & 33 & +0.61 \\
\hline Malcolm J & 32 & +0.47 \\
\hline Marcus R & 27 & +0.89 \\
\hline Chris A & 27 & +0.48 \\
\hline Stephanie A & 26 & +0.53 \\
\hline Curtis $\mathrm{H}_{\text {_ }}$ & 26 & +0.73 \\
\hline Juana $B$ & 24 & +0.34 \\
\hline Ashley $\mathrm{H}_{\text {_ }}$ & 24 & +0.29 \\
\hline Douglas B & 23 & +0.67 \\
\hline Brian G & 23 & +0.61 \\
\hline Ben T & 23 & +0.43 \\
\hline Alicia $L_{\text {_ }}$ & 23 & +0.58 \\
\hline Jeffrey B & -19 & +0.47 \\
\hline Megan $\mathrm{H}_{2}$ & 18 & +0.52 \\
\hline Antonio $\mathrm{F}$. & & +0.10 \\
\hline
\end{tabular}

\section{FIGURE 4}

CBM Class Report, Pages 4 and 5 ranks students according to their most recent CBM scores and, for each student, shows the weekly rate of growth.

PEER TUTORING ASSIGNMENTS

Teacher: Mrs. London

Report through 2/20

\begin{tabular}{|c|c|c|}
\hline M2Multiplying by 1 digit & First Coach & Second Coach \\
\hline & $\begin{array}{l}\text { Amy C } \\
\text { Darius M } \\
\text { Malcolm J } \\
\text { Chantel G } \\
\text { Stephanie A }\end{array}$ & $\begin{array}{l}\square \text { Antonio F } \\
\text { 四 Megan H } \\
\square \text { Marcus R } \\
\square \text { Ashley H } \\
\text { 組 Jasmin K }\end{array}$ \\
\hline \multirow[t]{2}{*}{ D2 One-step dividing } & First Coach & Second Coach \\
\hline & $\begin{array}{l}\text { Ben } T \\
\text { Juana B }\end{array}$ & $\begin{array}{l}\text { 四 Alicia L } \\
\text { 四 Jeffrey B }\end{array}$ \\
\hline \multirow[t]{2}{*}{ NCNumber concepts } & First Coach & Second Coach \\
\hline & $\begin{array}{l}\text { Lindsey S } \\
\text { Lakeisha M } \\
\text { Chris A }\end{array}$ & $\begin{array}{l}\text { 曲 Curtis H } \\
\text { DI Brian G } \\
\text { Douglas B }\end{array}$ \\
\hline
\end{tabular}




\section{CLASS STATISTICS: Computation+Applications}

Teacher: Mrs. London

Report through 2/20

\section{Score}

$\begin{array}{ll}\text { Average score } & 72.0 \\ \text { Standard deviation } & 17.6 \\ \text { Discrepancy criterion } & 54.4\end{array}$

\section{Slope}

$\begin{array}{lr}\text { Average slope } & +1.34 \\ \text { Standard deviation } & 0.53 \\ \text { Discrepancy criterion } & +0.81\end{array}$

\section{Students identified with dual discrepancy criterion}

$\begin{array}{lcc} & \text { Score } & \text { Slope } \\ \text { Antonio F } & 33.0 & +0.35 \\ \text { Douglas B } & 46.0 & +0.51\end{array}$

\section{FIGURE 6}

\section{CBM Class Report, Page 7 identifies students performing at least 1 standard deviation below the class mean on performance level and rate of growth.}

(Webb, Troper, \& Fall, 1995), and reciprocity (Top \& Osguthorpe, 1987; Wiegmann, Dansereau, \& Patterson, 1992) to enhance learning outcomes. PALS relies on structured interaction because research (Fitz-Gibbon, 1977; Michaels \& Bruce, 1991; Palincsar \& Brown, 1989) indicates that open-ended discussions and explanations frequently are problematic, confused, and ineffective.

During peer tutoring, every student in the class is paired to work on a skill with which one student requires assistance and the other child can provide help. Peer-tutoring activities are designed for the comprehensive mathematics curriculum so that different dyads can work simultaneously on number concepts, counting, word problems, charts/graphs, money, measurement, geometry, or computation. During peer tutoring, each dyad works through 12-20 instances of its target type of problem on a problem sheet.

The tutor models a series of verbal statements or questions that the tutee can use as a guide to the problem's solution. Each statement requires a verbal or written action by the tutee. Statements differ by type of problem. The tutor responds every time the tutee writes any response. When the tutee is correct, the tutor circles the response and praises the tutee; when the tutee is incorrect or expresses confusion, the tutor provides as much additional help as necessary. Consequently, the nature of this additional help is not structured, requiring tutors to construct their own explanations routinely.

The problem sheet is divided into four problem sets of equal length. With the first set, the dyad completes the explanatory interaction just described. The tutee works the next problem set more independently while explaining the work to the tutor, and while the tutor listens, corrects incorrect statements and relies on the correction procedure used with the first problem set. Then the two students reverse roles and repeat the same sequence of activities. Thus, the peer tutoring in PALS involves gradual fading of a verbal rehearsal routine that incorporates high levels of feedback and participation by both students, with the students sharing the roles of teacher and student and routinely constructing their own explanations. Tutoring assignments, which change every 2 weeks, are based on the weekly CBMs that teachers administer.

Two weeks after tutoring begins, two types of helping and explaining lessons are introduced to enhance the quality of peer interactions. The first lesson covers principles for seeking elaborated help (i.e., ask for help; keep on asking until you understand) and for offering elaborated help (i.e., pay careful attention to your partner; if you think your partner needs help, offer to help and don't just give the answer; explain how your partner can find the answer, and if one explanation does not help, try another; ask your partner to explain your explanation back to you to find out if he or she really understands). The principles are addressed in one 30minute lesson adapted from Farivar and Webb (1991).

The second set of three lessons, each of which relies on videotaped vignettes, covers methods for providing conceptual mathematical explanations. These three lessons, which last 40, 40, and 15 minutes, encourage students to contextualize problem situations, to represent quantities with visual images or physical materials, and to discuss strategies for solutions.

PALS peer tutoring translates these goals into five methods that students can use to provide conceptual mathematical explanations to peers:

1. Build number sentences incorporating real-life examples that are interesting and easy to picture in your head.

2. Make marks or pictures that stand for the numbers.

3. Use manipulatives so your partner can move and touch things that stand for the numbers.

4. Discuss the meaning of the numbers by explaining what the numbers stand for, talking about why the problem must be worked in a certain way, or discussing if and why the answer does or does not make sense. 
5. Ask step-by-step questions that begin with what, where, when, how, and why (see Fuchs et al., 1997, for examples of each method).

Once each week, following a tutoring session, teachers lead a 5-minute debriefing session in which they (a) ask if anyone has received an explanation that really helped; (b) ask the students to describe how they decided what their tutees needed help with; (c) solicit descriptions of helpful explanations; (d) require the class to classify the explanations; and (e) refer at least once to each of the above five methods.

\section{Evidence of Math PALS Effectiveness}

The combined CBM and tutoring methods have been shown to effect better mathematics (and reading) achievement in a range of students who participate in general education classrooms (e.g., Fuchs et al., 1997). Based on evidence of its effectiveness, Math PALS has been designated an "effective practice" by the Program Effectiveness Panel, U.S. Department of Education.

\section{AN R \& D MODEL FOR EDUCATION INNOVATIONS WITH LASTING POWER}

The literature commenting on the research-to-practice gap emphasizes the need for meaningful collaboration between researchers and practitioners in the development and evaluation of treatments, combined with nontraditional staff-development activities (Hamilton \& Richardson, 1995). We therefore conceptualized an R \& D model for effective practitioner-research collaboration and staff development, which should promote sustained implementation of innovative, validated practices in the schools.

This model relies on ongoing collaboration between university researchers and school-building teachers to (a) reflect on teachers' goals for innovation and to collaboratively specify and formatively evaluate education innovations that fit well within typical classrooms, (b) collaboratively design evaluations of those treatments, and (c) participate collaboratively in the formal evaluation of those treatments. This model has three stages.

The first stage involves implementing a piloting process in which teachers reflect on their needs and concerns and specify and formatively evaluate the innovations. In this stage, teachers work in collaboration with university personnel to constantly fine-tune and implement an innovation until that innovation seems to be classroom-, teacher-, and student-friendly, as well as effective.

Stage 2 is when formal testing of the innovation takes place. In this phase, schools or classrooms are assigned randomly to treatments, which are compared in terms of their capacity to promote student learning and the extent of satisfaction they engender in teachers and students. Each year, one component of the innovation is tested; during summers, teachers collaborate with the university staff to identify areas for revision and to specify the upcoming year's research design.

In Stage 3, the innovation is "scaled up," whereby schools, districts, and state departments locally and nationally provide support for teachers to implement the innovation. We illustrate this model by describing the R \& D process by which Math PALS was implemented.

\section{Stage 1}

During Stage 1, we worked with seven teachers, each in a different school, to pilot Math PALS. We had some ideas about how classwide CBM and peer tutoring might be combined for effective, feasible use in general education classrooms, and we began our pilot year with an initial operationalization. Teachers implemented this initial version of Math PALS for about 2 weeks, while we watched and helped in their classrooms.

At the end of 2 weeks, we met with each teacher, who provided us with ideas for how to improve the program. We integrated the feedback from these seven teachers, along with our own classroom observations, to formulate a second version of Math PALS, which the teachers in turn implemented for another 2 weeks. We then met again with each teacher and reformulated the program in response to their feedback and our observations.

This iterative process occurred throughout one school year. At the end of that school year, we had in hand a collaboratively developed Math PALS program, which we were confident was workable in a large number of classrooms. We did not, however, know how effective this program was. That brought us to Stage 2 of the R \& D model.

\section{Stage 2}

We began Stage 2 in the following year. In Stage 2, formal experimental studies were conducted to identify which components of the treatment are important to the overall program and to examine the effectiveness of that overall program. For example, our first experimental study on Math PALS examined which components of the CBM classwide report were important for enhancing planning and achievement and investigated the contribution of the reorganized classroom structure (the peer-tutoring arrangement) over and beyond that of the assessment-rich environment (i.e., CBM with class reports).

We therefore established three treatment groups.

1. In 10 classrooms, CBM was conducted weekly; every 2 weeks teachers received class reports that summarized student performance. 
2. In 10 classrooms, $\mathrm{CBM}$ also was conducted each week; the biweekly reports, however, not only summarized student performance but also provided instructional recommendations, including use of the peer-assisted learning strategies.

3. The remaining 20 classrooms were contrast classrooms, in which conventional planning procedures were used. Teachers implemented treatments for 25 school weeks. We studied effects on teacher planning, student achievement, and teacher satisfaction.

Results indicated that CBM decision-making strategies could be modified and extended from an individual focus to a classwide focus to allow general educators to implement $\mathrm{CBM}$ with large numbers of students. Teachers in both CBM treatments implemented CBM with a high degree of fidelity and expressed a high level of satisfaction with the assessment process and information. Nevertheless, results indicated that including the instructional recommendations in the class reports was important.

Thus, the recommendations, which included the tutoring component, were associated with significantly greater learning, with effect sizes ranging between .43 and .95 . These achievement differences were reflected in the teacher reports of their instructional planning: Teachers using the instructional recommendations reported that they relied more on tutoring and on computer-assisted instruction to help remediate students' problematic skills; they taught a greater variety of math skills; and they incorporated into their instructional programs more one-to-one instruction and more systematic motivation systems.

Important to student achievement, a main effect for treatment was revealed - an effect not mediated by students' prior learning histories (including the presence of a learning disability). Closer inspection of the achievement data did, unfortunately, raise some concern about the students with LD. In the most effective treatment (CBM with recommendations), the achievement of 9 of 10 non-LD low-achieving students surpassed the mean growth of their contrast treatment peers. By contrast, only 6 of 10 LD students surpassed the mean growth of their contrast treatment peers. Therefore, although CBM with instructional recommendations and a reorganized classroom tutoring structure seemed to be helpful, we concluded that additional forms of adaptation might be necessary to produce acceptable outcomes for a greater percentage of students with LD.

At the end of the school year, after we had analyzed the database we had collected, we brought in the teachers who had participated in this study. We shared our results and solicited their perspective on the findings. We also had discussions with these teachers about directions for the next year's study. Based on these discussions, we decided to focus on the need to prepare students carefully to work collaboratively.

As shown in the literature and as we observed in participating classrooms, children do not develop effective interactional styles as a natural consequence of experience in tutoring activities (Kohler \& Greenwood, 1990). Typically, students at the low end of the achievement continuum are omitted from group dynamics (O'Connor \& Jenkins, 1996). Open-ended discussions and explanations are problematic and confused (Cooper \& Cooper, 1984; Michaels \& Bruce, 1991; Palincsar \& Brown, 1989). Students rely on lectures and demonstrations, while providing few opportunities for peers to practice or apply explanations (Fuchs, Fuchs, Bentz, Phillips, \& Hamlett, 1994). And, explanations focus almost exclusively on procedural steps for solving problems rather than on conceptual underpinnings (Fuchs, Fuchs, Bentz et al., 1994).

To examine methods for enhancing children's helping behavior, we designed and tested three treatments, each of which was implemented by teachers for 18 school weeks (Fuchs, Fuchs, Hamlett, Karns, Phillips, \& Dutka, 1997). Twenty classrooms incorporated CBM and peer tutoring. In 10 of these classrooms, after the basic training in peer tutoring procedures, teachers conducted one lesson on principles for offering and requesting elaborated help, in which children provide explanations that lead peers to solve problems for themselves (rather than nonelaborated help, in which children merely provide answers or say that answers are wrong). The second group of $10 \mathrm{CBM}$ /tutoring classrooms received the elaborated helping lesson, along with instruction in methods for providing conceptual mathematical explanations. Finally, the contrast treatment, which consisted of 20 classrooms, relied on the same basal mathematics program but did not implement CBM or tutoring.

As documented in videotaped sessions, students in both $\mathrm{CBM} /$ tutoring conditions demonstrated a constructive style of interacting. Tutors relied minimally on lectures and demonstrations, and they rarely offered nonelaborated help. This corroborated prior work (e.g., Swing \& Peterson, 1982; Webb \& Farivar, 1994) showing that explicit training in elaborated helping can enhance students' interactional styles. Students in both $\mathrm{CBM} /$ tutoring conditions also achieved reliably better than students in the contrast condition, with impressive effect sizes of higher than .70 .

Important differences between conditions did, however, emerge. Two weeks after helping and explaining lessons were conducted, classroom observations revealed that students who had received the conceptual explanations lessons provided more helpful explanations to their partners. These short-term effects maintained over time. During tutoring sessions conducted 10 weeks after helping and explaining lessons had been completed, these tutors provided more conceptual explanations, with a large effect size of .77. 
Again, as with the previous year, we held focus group meetings with our participating teachers over the summer, in which we shared results, solicited their input, and worked collaboratively to formulate plans for the next year's study. Over time, using this iterative process, we built an empirically based, validated program: Math PALS. This brought us to Stage 3, with its focus on dissemination.

\section{Stage 3.}

In Stage 3, the validated practice is disseminated locally and nationally. At the local level, we contract with schools for our graduate students to instruct all teachers within a given school how to implement the practice. Then we provide low-level, ongoing technical assistance to ensure accurate implementation. Nationally, we work with state departments, school districts, and schools.

When working with state departments and school districts, we require teams of professionals from a given school (i.e., a classroom teacher, a special educator, a school psychologist, and a principal) to attend workshops as a collaborative team. At the end of the session, each team develops an implementation plan with specific timelines. Then we train their local professional development staff to provide ongoing technical assistance.

\section{CP ELEMENTARY SCHOOL: A CASE STUDY IN SUSTAINING RESEARCH-BASED PRACTICE}

CP Elementary School is a Title 1 school within the Metropolitan-Nashville Public Schools, with more than half of its 400 students receiving reduced or free lunches. None of the teachers at CP Elementary School worked with us during the Math PALS pilot year. At the beginning of our first Stage 2 study, we visited CP Elementary School to meet with the entire staff. We described Math PALS and the focus of that year's study. Three third-grade teachers volunteered to be assigned randomly to the three treatment groups.

During that first study year, other teachers at CP Elementary School became familiar with Math PALS via occasional informal observations of the experimental classrooms. The next year, when we returned to meet with the entire school staff to solicit participation in the second experimental study, all but two teachers volunteered to participate.

Over the next 5 years, we conducted many formal studies at CP Elementary, with similarly broad-based participation. During that time, math test scores on the annual statewide assessment at CP Elementary School skyrocketed - and differences in performance between the Math PALS and control classes were clear. The teachers took notice.
At the end of our research project, when we were confident that Math PALS was effective and doable, we no longer had research monies with which to support CP Elemenary School's implementation of Math PALS. Given the school's performance on the statewise assessment, however, teachers were determined to find resources to permit continued use of Math PALS - this time for the entire school (rather than for the teachers who had been assigned to experimental treatment groups). One teacher, Ms. CP, was particularly stubborn on this issue. She was determined that the school could implement Math PALS independent of the researchers, using the school's discretionary Title 1 monies. The teacher was relentless; the principal cooperated.

To implement Math PALS independently, CP set up a computer lab and assigned its Title 1 Coordinator the task of coordinating both the lab and the Math PALS implementation. We met with Ms. CP and the Title 1 Coordinator to provide them with a master set of all materials and an outline organizing the activities and required timelines for implementing Math PALS. CP Elementary School then identified the least expensive strategy for duplicating all required materials, and our computer programmer, Carol Hamlett, helped the Title 1 Coordinator network the CBM software in the school's computer lab. The school staff then developed its plan for using Math PALS. Staff members agreed on timelines for training their classes in (a) taking the CBM tests, (b) entering scores into the CBM software at the computer lab, and (c) peer tutoring.

In the first year, the school ran into some "bumps in the road" toward implementation. For example, the photocopy contractor copied all the CBM tests sideways on the paper, thereby systematically cutting off one-third of each assessment. This copying had to be redone completely. In addition, the school realized that it lacked a mechanism for training new teachers, who were totally unfamiliar with Math PALS, to use the methods. Understandably, it took a year of unanticipated difficulties before CP Elementary School could experience smooth implementation.

Fortunately, the school also had "sampled" the benefits of using Math PALS during its participation in the experimental studies. So, the staff knew that Math PALS was enjoyable for the teachers as well as the children. And, significantly, they knew that with Math PALS, their scores on the statewide assessment would be impressive. Consequently, the teachers in CP Elementary, led by Ms. CP and supported by the principal, persevered.

That initial year of independent Math PALS implementation occurred more than 5 years ago. After that first year, copying was accomplished correctly; in fact, it was completed in the spring of the preceding year so each teacher had in his or her possession, on the first day of school, a shrink-wrapped package with all the materials needed to implement Math PALS. 
Moreover, with schoolwide implementation, the demands on teachers to teach their children about CBM and peer tutoring decreased at all levels except second grade, when the students learned to do Math PALS for the first time. At higher grades, the students already were knowledgeable about Math PALS, requiring teachers only to review the procedures. Nevertheless new teachers continue to require initial training in Math PALS. So CP Elementary School arranges for new teachers to participate in annual Math PALS workshops at Vanderbilt University.

For more than 5 years, CP Elementary School has implemented Math PALS independently with great success. Based in large part on its implementation of Math PALS and the value-added scores on the statewide assessment, CP Elementary School recently won Tennessee's Award for Best Title 1 Plan. The school's value-added scores in math exceeded 200, which means that math improvement for children at CP Elementary School was more than twice the national average.

\section{PRINCIPLES FOR SUSTAINING RESEARCH-BASED PRACTICES}

How did CP Elementary School manage to sustain schoolwide use of Math PALS? Based on our observations of teachers at CP Elementary, as well as interviews with the staff, we propose five principles for sustaining researchbased practices.

1. The importance of a key individual. In adopting and sustaining research-based practices within schools, one individual can have a tremendous impact. This is clearly illustrated by Ms. CP, who made up her mind that she could not teach without Math PALS. She decided that she would find a way by which she and her teaching colleagues could implement Math PALS even though the research project had ended. Without Ms. CP, we believe that CP Elementary School likely would not have continued to implement Math PALS, even though a majority of teachers at the school had enjoyed the program and believed that their children had benefited from their participation in the research project.

2. Control of resources. Even with Ms. CP, the school needed some discretionary money that it could allocate to Math PALS. Sustaining the implementation of effective, innovative practices requires resources. If schools are to adopt and sustain use of validated innovations, they must have some discretionary decision making authority over staffing and money expenditures. Schools with such discretionary decision making have a greater probability of implementing and sustaining research-based practices.

3. Accountability for student outcomes. CP Elementary School's schoolwide, independent adoption of Math PALS illustrates the potential, positive power of accountability for student outcomes. During the Math PALS experimental research stage, the $\mathrm{CP}$ teachers and principal took notice of the difference in math outcomes between its Math PALS and control classes on the statewide assessment. The school district also took notice. And Ms. CP especially took notice. Maintaining this pattern of strong achievement has served as an important motivation in CP Elementary School's decision to sustain implementation of Math PALS. Although accountability reform and the testing that accompanies that reform can have unanticipated negative consequences (Fuchs \& Fuchs, 1999), this case study provides evidence in support of the intended positive effects: Accountability should drive adoption of effective practices.

4. Tolerance for initial implementation difficulties. The CP Elementary School case study also illustrates the necessity of patience, because initial implementation difficulties with any innovation can by expected. CP Elementary had difficulties they had not foreseen. The school, however, was sufficiently committed to successful implementation so it persevered in the face of those obstacles until arriving at a smooth, efficient strategy for implementing the practice.

Schools need leaders (in this case, Ms. CP, the Title 1 Coordinator, and the principal) with the wisdom to expect, tolerate, and address initial implementation problems without simply giving up the initiative. These school-based leaders should assure their colleagues that implementation will improve with practice over time. Anticipating the need for time and patience is critical.

5. Recognizing accomplishments. Everyone has to be recognized for activities that require more than typical effort. And, clearly, sustaining the use of research-based practices necessitates added effort. For that effort, teachers and schools that sustain implementation of research-based innovations have to be recognized in various ways: by fellow teachers, by principals, by parents, or by external sources. As a function (in large part) of its work in implementing Math PALS, CP Elementary School won a prestigious Title 1 award. The school district also acknowledged these accomplishments. Recognition is an important variable in sustaining implementation of research-based practices over time.

\section{CONCLUSIONS}

With respect to the reform literature, the issue of participation is probably most timely because the reform literature often emphasizes that education practice has to be personalized at the school level. This suggests that an innovation such as Math PALS, which has been developed with a handful of teachers and tested formally in a large number of classrooms, cannot be used by teachers who did not participate in those R \& D efforts. We disagree. 
Based on our work with Math PALS and other innovations in the local schools as well as nationally, we distinguish between two types of participation: personal participation in the development of an innovation versus initial participation by a representative group of teachers. We have found that personal participation in developing an innovation is not necessary for others to adopt, implement, and sustain that research-based practice.

Although personal participation seems to be unnecessary, though, we do believe in the importance of having a relatively large, "representative" group of teachers very much involved in the R \& D process. Ongoing participation in that process by a representative set of teachers is critical to ensure that the innovation, as it is eventually conceptualized and formatted, is suitable for implementation in a variety of everyday classrooms by a variety of everyday teachers.

This conclusion creates an optimism we share with many of our researcher colleagues across the country-optimism for the scalability of research-based education innovations. When those innovations are designed via strong, ongoing collaboration between researchers and teachers, teachers can view the final product as important, and one that can be sustained over time.

Of course, the education setting must be conducive for implementation and sustainability. The variables that favor adopting and sustaining innovations include a strong schoolbased individual (teacher, principal, parent) who promotes the innovation; a strong focus on student outcomes; time, patience, and support for school staffs to learn how to use the innovation in an efficient manner; and appropriate recognition for accomplishments.

\section{REFERENCES}

Bahr, M. W., Fuchs, D., Fuchs, L. S., Fernstrom, P. L., \& Stecker, P. (1993). Effectiveness of student versus teacher monitoring during prereferral intervention. Exceptionality, 4, 17-30.

Cooper, C. R., \& Cooper, R. G. (1984). Skill in peer learning discourse. In S.A. Kuczaf (Ed.), Discourse development (pp. 89-102). New York: Springer-Verlag.

Deno, S. L. (1985). Curriculum-based measurement: The emerging alternative. Exceptional Children, 52, 219-232.

Deno, S. L. (1994). Effects of support conditions on teachers' instructional adaptation and student learning. Paper presented at the second annual Pacific Coast Research Conference, La Jolla, CA.

Farivar, S., \& Webb, N. M. (1991). Helping behavior activities handbook. Los Angeles: University of California, Graduate School of Education.

Fitz-Gibbon, C. T. (1977). An analysis of the literature of cross-age tutoring. Durham, UK (ERIC Document Reproduction Service No. ED 148-807).

Fuchs, D., \& Fuchs, L. S. (1988). Mainstream assistance teams to accommodate difficult-to-teach students in general education. In J. L.Graden, J. E. Zins, \& M. J. Curtis (Eds.), Alternative educational delivery systems: Enhancing instructional options for all students (pp. 49-70). Washington, DC: National Association of School Psychologists.
Fuchs, D., \& Fuchs, L. S. (1989). Exploring effective and efficient prereferral insterventions: A component analysis of behavioral consultation. School Psychology Review, 18, 260-283.

Fuchs, D., \& Fuchs, L. S. (1991). Mainstream assistance teams: A prereferral intervention for difficult-to-teach students. In G. Stoner, M. Shinn, $\& \mathrm{H}$. Walker (Eds.), Interventions for achievement and behavior problems (pp. 241-267). Washington, DC: National Association of School Psychologists.

Fuchs, D., Fuchs, L. S., Bahr, M., Fernstrom, P. J., \& Stecker, P. M. (1990). Prereferral intervention: A prescriptive approach. Exceptional Children, 56, 493-515.

Fuchs, D., Fuchs, L. S., Gilman, S., Reeder, P., Bahr, M., Ferstrom, P., \& Roberts, H. (1990). Prereferral intervention through teacher consultation: Mainstream assistance teams. Academic Therapy, 25, 263-276.

Fuchs, L. S., \& Fuchs, D. (1999). Performance assessment using complex tasks: Implications for children with high-incidence disabilities. In R. Gallimore, C. Birnheimer, D. MacMillan, D. Speece, \& S. Vaughn (Eds.), Developmental perspectives on high-incidence disabilities (pp. 199-222). Mahwah, NJ: Erlbaum.

Fuchs, L. S., Fuchs, D., Bentz, J., Phillips, N. B., \& Hamlett, C. L. (1994). The nature of student interactions during peer tutoring with and without training and experience. American Educational Research Journal, $31,75-103$

Fuchs, L. S., Fuchs, D., Phillips, N. B., Hamlett, C. L., Karns, K., \& Dutka, S. (1997). Enhancing students' helping behavior during peer tutoring with conceptual mathematical explanations. Elementary School Journal, 97, 223-250.

Fuchs, L. S., Fuchs, D., Hamlett, C. L., Phillips, N., \& Bentz, J. (1994). Classwide curriculum-based measurement: Helping general educators meet the challenge of student diversity. Exceptional Children, 60, 518-537.

Fuchs, L. S., Fuchs, D., Hamlett, C. L., Phillips, N., \& Karns, K. (1995). General educators' specialized adaptation for students with learning disabilities. Exceptional Children, 61, 440-459.

Fuchs, L. S., Fuchs, D., Karns, K., \& Phillips, N. (1994). Peer-mediated mathematics instruction: A manual (Available from Box 328 Peabody, Vanderbilt University, Nashville, TN 37203).

Fullan, M. (1991). The new meaning of educational change. New York: Teachers College Press.

Gersten, R. M., Woodward, J., \& Morvant, M. (1992). Refining the working knowledge of the process of coaching as a means to translate research to classroom practice. Educational Leadership, 49(7), 34-38.

Graham, S., \& Harris, K. R. (1989). Components analysis of cognitive strategy instruction: Effects on learning disabled students' composition and self-efficacy. Journal of Educational Psychology, 81, 353-361.

Greenwood, C. R., Delquadri, J. C., \& Hall, R. V. (1989). Longitudinal effects of classwide peer tutoring. Journal of Educational Psychology, 81, 371-383.

Hamilton, M.L., \& Richardson, V. (1995). Effects of the culture in two schools on the process and outcomes of staff development. Elementary School Journal, 95, 367-385.

Huberman, M. (1983). Recipes for buy kitchens. A situational analysis of routine knowledge use in schools. Knowledge: Creation, diffusion, utilization, 4, 478-510.

Kaestle, C. F. (1993). A federal perspective on improving practices, programs, and policies in special education. Evaluation and Program Planning, 16, 263-269.

Kohler, F. W., \& Greenwood, C. R. (1990). Effects of collateral peer supportive behaviors within the classwide peer tutoring program. Journal of Applied Behavior Analysis, 23, 307-322.

Malouf, D. B., \& Schiller, E. P. (1995). Practice and research in special education. Exceptional Children, 61, 441-424. 
Michaels, S., \& Bruce, C. (1991). Discourses on the seasons (Technical Report). Champaign: University of Illinois, Reading Research and Education Center.

Nelson, J. R., Smith, D. J., Taylor, L., Dodd, J. M., \& Reavis, K. (1992). A statewide survey of special education administrators regarding mandated prereferral interventions. Remedial \& Special Education, 13, 34-39.

O'Connor, R. E., \& Jenkins, J. R. (1996). Cooperative learning as an inclusion strategy: The experience of the special education students. Exceptionality, 6, 29-52.

Palincsar, A. S., \& Brown, A. L. (1989). Classroom dialogues to promote self-regulated comprehension. In J. Brophy (Ed.), Advances in research on teaching, Vol. 1 (pp. 35-71), New York: JAI Press.

Sindelar, P. T., Griffin, C. C., Smith, S. W., \& Watanabe, A. K. (1992). Prereferral intervention: Encouraging notes on preliminary findings. Elementary School Journal, 92, 245-259.

Swing, S. R., \& Peterson, P. L. (1982). The relationship of student ability and small group interaction to student achievement. American Educational Research Journal, 19, 259-274.

Top, B. I., \& Osguthorpe, R. T. (1987). Reverse role tutoring: The effects of handicapped students tutoring regular class students. Elementary School Journal, 22, 351-367.

Walberg, H. J. (1984). Improving the productivity of America's schools. Educational Leadership, 41(8), 19-27.
Webb, N. M., \& Farivar, S. (1994). Promoting helping behavior in cooperative small groups in middle school mathematics. American Educational Research Journal, 31, 369-395.

Webb, N. M., Troper, J., \& Fall, J. R. (1995). Constructive activity and learning in collaborative small groups. Journal of Educational Psychology, 87, 406-423.

Wiegmann, D. A., Dansereau, D. F., \& Patterson, M. E. (1992). Cooperative learning: Effects of role playing and ability on performance. Journal of Experimental Education, 60, 109-116.

Zook, K. B., \& DiVesta, F. J. (1989). Effects of overt controlled verbalization and goal specific search on acquisition of procedural knowledge in problem solving. Journal of Educational Psychology, 81, 220-225

This research and development was supported in part by Grants \#H023G50005, \#H180E20004, and \#H023E90020 from the U.S. Department of Education, Office of Special Education Programs, and Core Grant \#HD15052 from the National Institute of Child Health and Human Development to Vanderbilt University. Statements do not reflect the position or policy of these agencies, and no official endorsement by them should be inferred. 


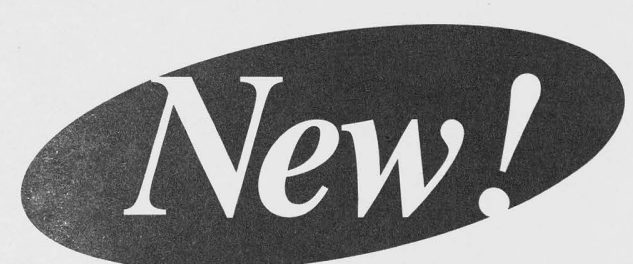

\section{Functional Behavioral Assessment}

\section{A Systematic Process for Assessment and Intervention in General and Special Education Classrooms}

\section{Mary E. McConnell, Turner School District, Kansas City, Kansas}

Functional assessment can be overwhelming to educators who are not familiar with the process. This book is designed specifically for persons who have limited training in applied behavior analysis and functional assessment procedures.

This easy-to-use manual will help educators understand the purpose and meaning of the functional behavior assessment process and how to identify and assess behavior. It shows how to develop and write effective Behavior Intervention Plans using data collected during the functional assessment.

\section{SPECIAL FEATURES}

- Presents step-by-step procedures for conducting functional assessments

- Shows how to write Behavior Intervention Plans and select interventions

- Discusses data collection

- Includes dozens of checklists and plan sheets for working with Behavior Intervention Plans.

\section{CONTENTS}

1. Introduction to IDEA and Functional Assessment

2. The Function of Functional Assessment

3. Functional Assessment Process

4. Behavioral Intervention Plans

5. Appendix Forms and Planning Sheets

112 pages/0009/paperback/81/2 x 11/ISBN 0-89108-277-8/\$24.95

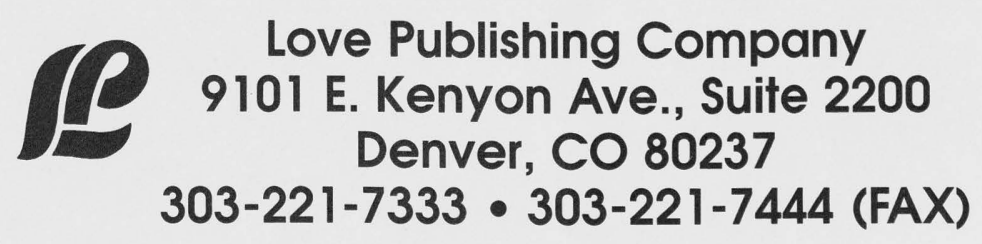




\section{Professional update}

\section{American Educational Research Association}

April 10-14, 2001

Seattle, WA

Contact: (202) 223-9485

http://www.aera.net

\section{Council for Exceptional Children}

April 18-21, 2001

Kansas City, MO

Contact: (800) 486-5773

http://www.cec.sped.org

\section{National Association of School Psychologists}

April 17-21, 2001

Washington, DC

Contact: (301) 657-0270

http://www.naspweb.org

\section{PERMISSIONS AND COPYRIGHT}

All rights are reserved. No part of this publication may be reproduced, photocopied, faxed, stored in a retrieval system, or transmitted in any form or by any means, electronic, mechanical, recording or otherwise, without the prior written permission of the publisher.
Back issues are available for sale. Reproduction requires permission and payment of fees. It is illegal and a violation of federal copyright law to reproduce this publication without permission. Direct all inquiries to the permissions editor. 